\title{
Does low-cost GIC have the same survival rate as high-viscosity GIC in atraumatic restorative treatments? \\ A RCT. Braz Oral Res. 2019;33:e125.
}

\author{
Correct author's: \\ Where is read: \\ Marcoeli Silva de MOURA ${ }^{(a)}$ \\ Geovanna Peres de SOUSA ${ }^{(a)}$ \\ Maria Hellen Sâmia Fortes BRITO(a) \\ Mikaelle Claro Costa SILVA ${ }^{(a)}$ \\ Marina de Deus Moura de LIMA ${ }^{(a)}$ \\ Lúcia de Fátima Almeida de Deus MOURA ${ }^{(a)}$ \\ Cacilda Castelo Branco LIMA ${ }^{(a)}$ \\ It should read: \\ Marcoeli Silva de MOURA ${ }^{(a)}$ \\ Geovanna Peres de SOUSA ${ }^{(a)}$ \\ Maria Hellen Sâmia Fortes BRITO(a) \\ Mikaelle Claro Costa SILVA ${ }^{(a)}$ \\ Marina de Deus Moura de LIMA ${ }^{(a)}$ \\ Lúcia de Fátima Almeida de Deus MOURA ${ }^{(a)}$ \\ Renata Correa PASCOTTO(b) \\ Cacilda Castelo Branco LIMA ${ }^{(a)}$ \\ In pages 3, 5, 7 and 9 \\ Where is read: Moura MS, Sousa GP, Brito MHSF, Silva MCC, Lima \\ MDM, Lima CCB, et al. \\ It should read: Moura MS, Sousa GP, Brito MHSF, Silva MCC, Lima \\ MDM, Pascotto RC, et al.
}

